EESTI NSV TEADUSTE AKADEEMIA TOIMETISED. XI KÖIDE

FOOSIKALIS-MATEMAATILISTE JA TEHNILISTE TEADUSTE SEERIA. 1962, NR. 3

ИЗВЕСТИЯ АКАДЕМИИ НАУК ЭСТОНСКОИ ССР. ТОМ ХІ

СЕРИЯ ФИЗИКО-МАТЕМАТИЧЕСКИХ И ТЕХНИЧЕСКИХ НАУК, 1962, № 3

\title{
О ФОСФАТНОМ МАТЕРИАЛЕ ОБОЛОВЫХ ФОСФОРИТОВ
}

\section{А. лоог}

В основанин нижнего ордовика Эстонии залегают песчаники пакерортского горизонта. В этих кварцевых песчаниках встречаются фосфатные створки и фрагменты беззамковых брахиопод из семейства Obolidae. Линзовидные скопления створок оболид - так называемый оболовый конгломерат - образуют фосфатную руду со средним содержанием $\mathrm{P}_{2} \mathrm{O}_{5} 10-15 \%$. Здесь встречаются и хорошо окатанные гальки песчанистого фосфорита и отдельные мелкие зерна чистого фосфата кальция. Основная масса фосфата оболовых фосфоритов заключается в створках оболид.

Уже в 1861 году К. Шмидт $\left[{ }^{18}\right]$ обратил внимание на то, что раковины оболид фосфатные и их можно использовать как удобрение. Он впервые дал химический анализ оболіовх фосфоритов, предполагая, что створки состоят «из аморфного или вернее, органически образованного фторапатита».

После К. Шмидта многие исследователи делали разные предположения о фосфатном материале фосфорнтов Эстонии. А. Купфер [15], К. Гревингк $\left[^{12}\right]$, Я. Самойлов [9] и И. Курман [] утверждали, что створки оболид сложены фторапатитом.

А. Миквиц [17], изучая створки оболид под микроскопом, утверждал, что они построены из чередующихся пластинок фторапатита и карбоната кальция, что соответствует химическому анализу створок оболид, произведенному А. Купфером (табл. 1). М. Врангел $\left[{ }^{20}\right]$ же на основании своих собственных химических анализов, а также минералогических исследований П. Нигли считала, что створки состоят из хомогеңного фосфатного вещества, имеющего структуру карбонатапатита-штаффелита. Вслед за ней X. Винклер $\left[{ }^{19}\right]$, К. Лийдеман $\left[{ }^{16}\right]$ и К. Гэберт $\left[{ }^{13}\right]$ также называли фосфатное вещество створок штаффелитом и карбонатапатитом. А. Эпик $\left[{ }^{21}\right]$, основываясь на строении створок и химических анализах (табл. 1), утверждал, что створки оболид состоят из трех типов пластинок: апатитовидных, кальцитовых и гипсовых. Он предлагал условно называть вещество створок оболовым фосфоритом. Г. Бушинский $\left.{ }^{4}\right]$ указывал, что по химическому составу (табл. 2) вещество створок оболид близко к франколиту. Р. Кох $\left[{ }^{14}\right]$ поднимал вопрос о том, не состоят ли створки оболид из минерала вилкеита?

Қак видно из предыдущего, имеются различные соображения о строении и веществе створок оболид. Это объясняется использованием, в основном, только результатов химического анализа и несовершенством методики анализа.

Следует отметить, что в настоящее время отсутствует единое мнение о минералогическом составе фосфоритов. Принято считать, что главную массу фосфоритов слагают фосфаты кальіия, имеющие кристаллическую решетку типа апатита и принадлежащие к апатитовой группе.

А. Қазаков ["] на основе своих многолетних работ по изучению фосфоритов, а также рентгеноструктурных исследований О. Соймоновой и Н. Слудской [10] пришел к заклю- 
чению, что фосфаты всех фосфоритов принадлежат к фторапатиту. Многие другие нсследователи считают их также не самостоятельными минералами, а разновидностями апатита.

Таблица 1

Химические анализы чистых створок оболид

\begin{tabular}{|c|c|c|c|c|}
\hline \multirow{2}{*}{ Компоненты } & \multirow{2}{*}{$\begin{array}{c}\text { Створки } \\
\text { оболид из } \\
\text { Кингисеппа } \\
\text { (Ямбур- } \\
\text { га) * }\end{array}$} & \multicolumn{2}{|c|}{$\begin{array}{c}\text { Obolus apollinis } \\
\text { (typicus)** }\end{array}$} & \multirow{2}{*}{$\begin{array}{c}\begin{array}{c}\text { Schmidtites } \\
\text { celatus }\end{array} \\
\begin{array}{c}\text { брюшная } \\
\text { створка }\end{array} \\
\end{array}$} \\
\hline & & $\begin{array}{l}\text { брюшная } \\
\text { створка }\end{array}$ & $\begin{array}{l}\text { спинная } \\
\text { створка }\end{array}$ & \\
\hline $\begin{array}{l}\mathrm{H} . \mathrm{O} .\left(\mathrm{SiO}_{2}\right) \\
\mathrm{Al}_{2} \mathrm{O}_{3} \\
\mathrm{Fe}_{2} \mathrm{O}_{3} \\
\mathrm{FeS}_{2} \\
\mathrm{CaO} \\
\mathrm{MgO} \\
(\mathrm{K}, \mathrm{Na})_{2} \mathrm{O} \\
\mathrm{P}_{2} \mathrm{O}_{5} \\
\mathrm{SO}_{3} \\
\mathrm{CO}_{2} \\
\mathrm{~F} \\
\mathrm{Cl} \\
\mathrm{H}_{2} \mathrm{O} \text { (влажн.) } \\
\text { П.п.п. }\end{array}$ & $\begin{array}{l}0,53 \\
\overline{4,90} \\
\overline{-} \\
50,47 \\
0,62 \\
\overline{-} \\
36,57 \\
\overline{2,42} \\
3,31 \\
\overline{-} \\
\overline{2,57}\end{array}$ & $\begin{array}{c}0,67 \\
0,34 \\
0,97 \\
3,46 \\
50,22 \\
0,16 \\
\text { следы } \\
35,45 \\
1,21 \\
2,20 \\
2,77 \\
0,11 \\
0,89 \\
2,62\end{array}$ & $\begin{array}{c}0,46 \\
0,39 \\
2,76 \\
3,99 \\
49,22 \\
0,37 \\
-\overline{3} \\
34,93 \\
1,32 \\
2,07 \\
2,72 \\
\text { следы } \\
0,93 \\
2,54\end{array}$ & $\begin{array}{r}0,67 \\
\overline{3,17} \\
0,50 \\
50,95 \\
0,07 \\
\overline{-} \\
36,07 \\
1,84 \\
2,09 \\
2,79 \\
\overline{0,90} \\
2,59\end{array}$ \\
\hline $\begin{array}{l}\text { Сумма } \\
\mathrm{O} \text { соотв. F }\end{array}$ & $\begin{array}{r}101,39 \\
-1,59\end{array}$ & $\begin{array}{l}101,07 \\
-1,16\end{array}$ & $\begin{array}{r}101,70 \\
-1,14\end{array}$ & $\begin{array}{r}101,64 \\
-1,18\end{array}$ \\
\hline Сумма & 99,80 & 99,91 & 100,56 & 100,46 \\
\hline $\begin{aligned} \mathrm{F} & : \mathrm{P}_{2} \mathrm{O}_{5} \\
\mathrm{CO}_{2} & : \mathrm{P}_{2} \mathrm{O}_{5} \\
\mathrm{CaO} & : \mathrm{P}_{2} \mathrm{O}_{5}\end{aligned}$ & $\begin{array}{l}0,09 \\
0,06 \\
1,38\end{array}$ & $\begin{array}{l}0,08 \\
0,06 \\
1,41\end{array}$ & $\begin{array}{l}0,08 \\
0,06 \\
1,40\end{array}$ & $\begin{array}{l}0,08 \\
0,06 \\
1,41\end{array}$ \\
\hline
\end{tabular}

* Анализ А. Купфера [15].

** Анализы С. Паула $\left[{ }^{21}\right]$.

Принципиально иного мнения придерживается Г.-Бушинский $[2,3,4]$, различающий среди фосфатов фосфоритов пять самостоятельных минералов: фторапатит $\mathrm{Ca}_{10} \mathrm{P}_{6} \mathrm{O}_{24} \mathrm{~F}_{2}$; карбонатапатит $\mathrm{Ca}_{10} \mathrm{P}_{5} \mathrm{CO}_{23}(\mathrm{OH})_{3}$ (синоннмы - даллит, подолит); гидроксилапатит $\mathrm{Ca}_{10} \mathrm{P}_{6} \mathrm{O}_{24}(\mathrm{OH})_{2}$ (синонимы - остеолит, гидроапатит); франколит $\mathrm{Ca}_{10} \mathrm{P}_{5,2} \mathrm{C}_{0,8} \mathrm{O}_{23,2} \mathrm{~F}_{1,8}(\mathrm{OH})$ (синоним - штаффелит) и его «аморфная» разновидность - коллофан; курскит $\mathrm{Ca}_{10} \mathrm{P}_{4,8} \mathrm{C}_{1,2} \mathrm{O}_{22,8} \mathrm{~F}_{2}(\mathrm{OH})_{1,2}$ (синоним - гроднолит).

У разных исследователей значения этих наименований были разные. А. Бетехтин ['] описывал, например, многие из этих разновидностей как самостоятельные минералы.

Химические анализы створок оболид (табл. 1 и 2) близки к франколиту, теоретический состав которого по Г. Бушинскому $\left[{ }^{4}\right]$ следующий: $\mathrm{CaO}=48,52 \% ; \quad \mathrm{P}_{2} \mathrm{O}_{5}=$ $=37,14 \% ; \mathrm{CO}_{2}=3,54 \% ; \mathrm{CaF}_{2}=7,07 \%$ и $\mathrm{Ca}(\mathrm{OH})_{2}=3,73 \%$. Примерно такие же соотношения главных компонентов в анализах створок оболид.

Так как не удалось определить содержание кристаллизационной воды в створках оболид, избыточный кальций связывается с гидроксильной группой. Присутствие $\mathrm{SO}_{3}$ в створках оболид объясняется изоморфным замещением $\mathrm{PO}_{4}^{3-}$ ионом $\mathrm{SO}_{4}^{2-}$ в фосфатной решетке [3]. 
$\mathrm{CO}_{2}$ входит в решетку фосфатного минерала (франколита), а не связана с кальцитом, адсорбированным тонкодисперсным фторапатитом, как это утверждает А. Казаков [6]. Этим и объясняется почти неизменное отношение $\mathrm{CO}_{2}: \mathrm{P}_{2} \mathrm{O}_{5}$ в створках оболид (табл. 1 и 2).

таблица 2

Химические анализы чистых створок оболид

\begin{tabular}{|c|c|c|c|}
\hline Компоненты & $\begin{array}{c}\text { Анализ } \\
\text { чистых ство- } \\
\text { рок оболид, } \\
\text { по Г. Бу- } \\
\text { шинскому [4] }\end{array}$ & $\begin{array}{l}\text { Obolus sp. } \\
\text { из Маарду * }\end{array}$ & $\begin{array}{l}\text { Obolus sp. } \\
\text { из Иру * }\end{array}$ \\
\hline $\begin{array}{l}\mathrm{SiO}_{2} \\
\mathrm{Al}_{2} \mathrm{O}_{3} \\
\mathrm{TiO}_{2} \\
\mathrm{FeO} \\
\mathrm{Fe}_{2} \mathrm{O}_{3} \\
\mathrm{MnO} \\
\mathrm{CaO} \\
\mathrm{MgO} \\
\mathrm{Na}_{2} \mathrm{O} \\
\mathrm{K}_{2} \mathrm{O} \\
\mathrm{P}_{2} \mathrm{O}_{5} \\
\mathrm{As}_{2} \mathrm{O}_{5} \\
\mathrm{SO}_{3} \\
\mathrm{CO}_{2} \\
\mathrm{CaF}_{2} \\
\mathrm{~F} \\
\mathrm{Cl} \\
\mathrm{FeS}_{2} \\
\mathrm{H}_{2} \mathrm{O} \text { (влажн.) } \\
\text { П.п.п. }\end{array}$ & $\begin{array}{cl} & 0,62 \\
& 0,35 \\
\text { не } & 0,04 \\
\text { опред. } & 0,94 \\
0,10 \\
50,61 \\
0,42 \\
0,59 \\
0,43 \\
35,63 \\
\text { не } \quad \text { опред. } \\
1,31 \\
2,21 \\
- \\
2,79 \\
\text { не } \\
\text { опред. } \\
3,37 \\
\text { не } \\
\text { опред. } \\
2,58\end{array}$ & $\begin{array}{c}1,62 \\
0,30 \\
0,002 \\
- \\
0,55 \\
0,10 \\
45,98 \\
0,48 \\
0,21 \\
0,06 \\
35,00 \\
0,008 \\
1,20 \\
3,57 \\
6,38 \\
- \\
0,02 \\
4,18 \\
0,92 \\
5,51\end{array}$ & $\begin{array}{c}0,64 \\
0,53 \\
0,002 \\
-\overline{0} \\
0,84 \\
0,10 \\
47,20 \\
0,64 \\
0,22 \\
0,04 \\
36,20 \\
0,008 \\
1,22 \\
3,10 \\
5,82 \\
- \\
0,017 \\
3,13 \\
1,28 \\
5,97\end{array}$ \\
\hline O соотв. F & $-1,18$ & & \\
\hline $\begin{array}{l}\text { Сумма } \\
\mathrm{F}: \mathrm{P}_{2} \mathrm{O}_{5} \\
\mathrm{CO}_{2}: \mathrm{P}_{2} \mathrm{O}_{5} \\
\mathrm{CaO}: \mathrm{P}_{2} \mathrm{O}_{5} \\
\mathrm{C} \text { (орг.) }\end{array}$ & $\begin{array}{r}99,20 \\
0,08 \\
0,06 \\
1,42 \\
1,28\end{array}$ & $\begin{array}{r}99,60 \\
0,08 \\
0,09 \\
1,44\end{array}$ & $\begin{array}{c}99,707 \\
0,08 \\
0,10 \\
1,42\end{array}$ \\
\hline
\end{tabular}

* Анализы Р. Отта.

По Г. Бушинскому [4], наиболее характерно отличается курскит от франколита отношением $\mathrm{CO}_{2}: \mathrm{P}_{2} \mathrm{O}_{5}$ и отчасти $\mathrm{F}: \mathrm{P}_{2} \mathrm{O}_{5}$.

$\begin{array}{lrr} & \mathrm{CO}_{2}: \mathrm{P}_{2} \mathrm{O}_{5} & \mathrm{~F}: \mathrm{P}_{2} \mathrm{O}_{5} \\ \text { франколит } & 0,07 \pm 0,04 & 0,08+0,02 \\ \text { курскит } & 0,18+0,03 & 0,10+0,02\end{array}$

Он также приводит очень интересную диаграмму группировки фосфоритов СССР в координатах отношений $\mathrm{CO}_{2}: \mathrm{P}_{2} \mathrm{O}_{5}$ и $\mathrm{F}: \mathrm{P}_{2} \mathrm{O}_{5}$ (фиг. 1).

На эту диаграмму нами нанесены результаты 10 химических анализов чистых створок оболид из эстонского оболового фосфорита и 6 анализов фосфоритной руды кварцевого песчаника с обломками створок оболид (нанесены только приборы фосфо- 
ритной руды без карбонатного цемента). Почти все результаты анализов попадают в поле франколитовых фосфоритов.

Интересно еще отметить, что по трем анализам фосфоритных галек - песчанистого фосфорита, имеющих фосфатный цемент двух стадий, отношения $\mathrm{CO}_{2}: \mathrm{P}_{2} \mathrm{O}_{5}$ и $\mathrm{F} . \mathrm{P}_{2} \mathrm{O}_{5}$ близки к отношенням, характерным для минерала курскита.

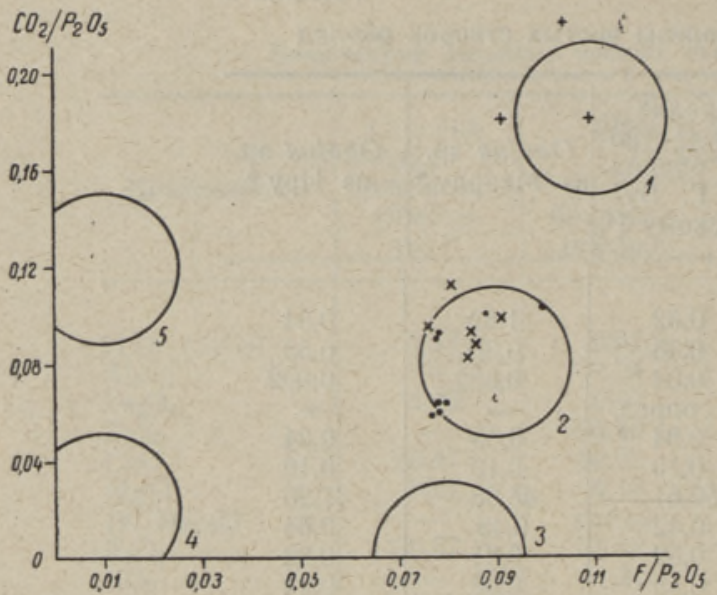

Фиг. 1. Диаграмма Г. Бушинского группировки фосфоритов СССР в координатах отношений $\mathrm{CO}_{2}: \mathrm{P}_{2} \mathrm{O}_{5}$ и $\mathrm{F}: \mathrm{P}_{2} \mathrm{O}_{5}$ 1 - курскнтовые фосфориты (желваковые); 2 - франколитовые фосфориты; 3 - фторапатит; 4 - гидроксил-апатитовые фосфориты; 5 - карбонат-апатитовые фосфориты.

- чистые створки оболид;

× - оболовый фосфорит;

+ - гальки песчанистого фосфорита.

По данным химического (табл. 1 и 2) и полуколичественного спектрального анализа (табл, 3) в чистых створках оболид содержание $\mathrm{Mn}, \mathrm{Pb}, \mathrm{Mg}, \mathrm{Fe}, \mathrm{Na}, \mathrm{Zn}, \mathrm{Ba}$ п TR больше, чем в оболовом фосфорите. $\mathrm{Mn}, \mathrm{Mg}$, $\mathrm{Na}$ и TR могут изоморфно входить в фосфатную решетку, замещая кальций.

Таблица 3

Содержание элементов в оболовом конгломерате (фосфорите) и чистых створках оболид (в \%) по данным полуколичественного спектрального анализа

\begin{tabular}{|c|c|c|c|c|c|c|}
\hline \multirow[b]{2}{*}{ Элементы } & \multicolumn{2}{|c|}{ Маарду } & \multicolumn{2}{|c|}{ Онтика } & \multicolumn{2}{|c|}{ Иру } \\
\hline & $\begin{array}{l}\text { Оболовый } \\
\text { фосфорит }\end{array}$ & $\begin{array}{l}\text { Чистые } \\
\text { створки }\end{array}$ & $\begin{array}{l}\text { Оболовый } \\
\text { фосфорит }\end{array}$ & $\begin{array}{l}\text { Чистые } \\
\text { створки }\end{array}$ & $\begin{array}{l}\text { Оболовый } \\
\text { фосфорит }\end{array}$ & $\begin{array}{l}\text { Чистые } \\
\text { створки }\end{array}$ \\
\hline $\begin{array}{l}\mathrm{Ag} \\
\mathrm{Ba} \\
\mathrm{Be} \\
\mathrm{Cr} \\
\mathrm{Cu} \\
\mathrm{Ga} \\
\mathrm{Ge} \\
\mathrm{Mo} \\
\mathrm{Ni} \\
\mathrm{Pb} \\
\mathrm{La} \\
\mathrm{Y} \\
\mathrm{Yb} \\
\mathrm{Sr} \\
\mathrm{V} \\
\mathrm{Zn} \\
\mathrm{Zr}\end{array}$ & $\begin{array}{l}\overline{\overline{0}} \\
0,0002 \\
\overline{-} \\
0,002 \\
- \\
\overline{-} \\
0,001 \\
0,02 \\
0,005 \\
0,02 \\
0,002 \\
0,1 \\
\overline{-} \\
0,006\end{array}$ & $\begin{array}{l}0, \overline{3} \\
0,0005 \\
\overline{-} \\
0,006 \\
\overline{-} \\
0, \overline{01} \\
0,001 \\
0,15 \\
\overline{0} \\
0,05 \\
0,008 \\
0,1 \\
0,001 \\
\overline{-} \\
0,006\end{array}$ & $\begin{array}{c}\overline{0} \\
0,02 \\
0,0005 \\
0,002 \\
0,002 \\
\overline{-} \\
0,002 \\
\overline{-} \\
0,02 \\
0,02 \\
0,02 \\
0,002 \\
0,2 \\
0,001 \\
0, \overline{0} \\
0,02\end{array}$ & \begin{tabular}{l}
0,0003 \\
0,04 \\
0,0008 \\
\multicolumn{1}{c}{-} \\
0,008 \\
0,002 \\
0,003 \\
$\overline{-}-\overline{0}$ \\
0,001 \\
0,15 \\
0,02 \\
0,09 \\
0,008 \\
0,1 \\
0,0007 \\
0,05 \\
0,006
\end{tabular} & $\begin{array}{l}0, \overline{0} \\
0,0002 \\
0,002 \\
0,005 \\
0,002 \\
\overline{-} \\
0,002 \\
0,009 \\
0,02 \\
0,05 \\
0,002 \\
0,5 \\
0,0002 \\
0,05 \\
0,02\end{array}$ & $\begin{array}{l}0,3 \\
0,0003 \\
\overline{-} \\
0,007 \\
\overline{-} \\
\overline{-} \\
0,001 \\
0,1 \\
0,02 \\
0,05 \\
0,008 \\
0,08 \\
0,- \\
0\end{array}$ \\
\hline
\end{tabular}

Не обнаружены: Sn, Co, Li, Sc, Sb, Tl, Ta, In, Bi и Cd. 
Химические анализы оболовых фосфоритов, выполненные в химико-аналитической лаборатории ИМГРЭ М. Чулковой, имеют содержание $\Sigma$ TR от 0,09 до $1,6 \%$. Органического вещества, по данным М. Врангел [ $\left.{ }^{20}\right]$, в створках оболид $0,87-3,0 \%$.

В оболовом конгломерате (фосфорите) встречаются не целые раковины, а отдельные створки и их фрагменты. Были ли они с самого начала фосфатными или представляют псевдоморфозы, как это утверждает М. Врангел [20]?

У всех створок оболид, независимо от вида, месторождения и их стратиграфического положення, всегда одинаковое содержание основных компонентов, входящих в состав фосфатного минерала (табл. 1 и 2). На это указывал уже А. Эпик [21]. По И. Курману $\left.{ }^{7}\right]$, в Ленинградской области и, по И. Андерсону и Н. Салбома [1"], в Швеции створки оболид имеют-такой же состав основных компонентов $\left(\mathrm{P}_{2} \mathrm{O}_{5}\right.$ $\sim 36 \%$ ). Следовательно, раковины оболид были с самого начала фосфатными. По данным А. Виноградова [5], и в раковинах рецентного беззамкового брахиопода Lingula anatina содержание $\mathrm{P}_{2} \mathrm{O}_{5}$ составляет $42,99 \%$.

Таблица 4

Межплоскостные расстояния (d) фосфатного минерала створок оболид; нефильтрованное $\mathrm{Cu}$ - излучение

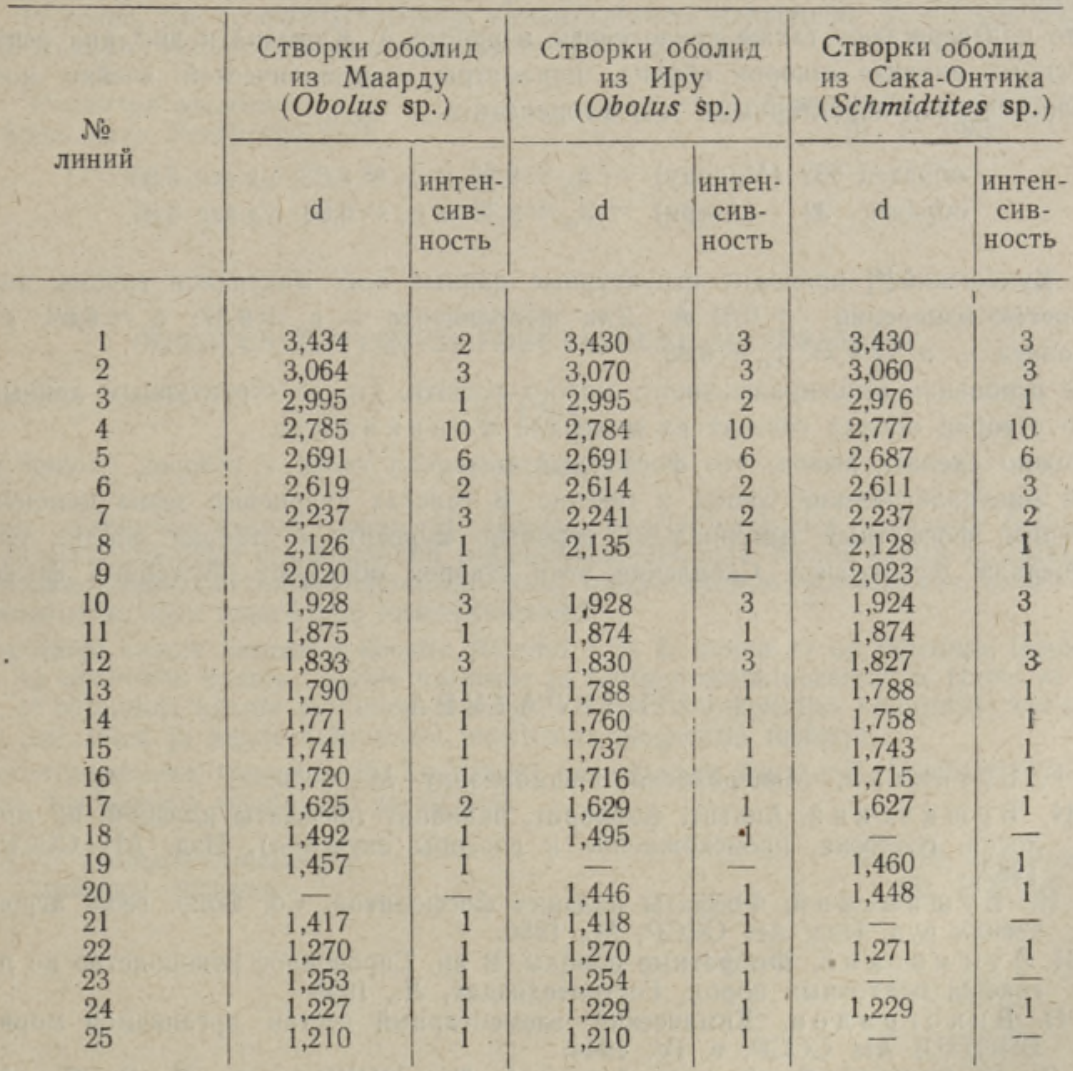

Микроскопическое изучение створок оболид показывает, что они состоят из двух типов чередующихся микроскопических пластинок. Одни из этих имеют вид тонкопористой гомогенной, как бы аморфной фосфатной массы, а другие - тонкой волокнистой кристаллической фосфатной массы. Некоторые волокна имеют белый цвет, a 
основная масса окрашена примесями органического вешества и гидроокислами железа в коричневый цвет. Не найдены карбонаты кальция и гипс. В шлифах створки оболид. наблюдаются в виде коричневых пластинок с показателем светопреломления от 1,597 до 1,603. В скрещенных николях большинство из них находится в положении постоянного затемнения, а некоторые имеют волнистое погасание. В поперечном сечении створки оболид иногда обнаруживают слабое двупреломление и плохо выраженную коноскопическую фигуру двухосного отрицательного (?) минерала.

Твердость фосфатного материала створок равна 5, а во внутренних частях створок местами меньше. Удельный вес створок, по данным А. Эпика [21], колеблется от 2,879 до 3,002 .

Цвет створок от светло-серого до черного, В темно-серых и черных створках между отдельными пластинками можно видеть кристаллики пирита. Черные створки Obolus sp. из Маарду содержат больше $\mathrm{Fe}_{2} \mathrm{~S}$, чем светло-серые створки Obolus sp. из Иру, что подтверждается химическими анализами (табл. 2).

В лаборатории рентгеноструктурного анализа Института строительства и строительных материалов АН ЭССР Р. Илбергом произведены на приборе УРС-50И анализы чистых створок оболид из Иру, Маарду и Сака-Онтика (табл. 4). Во всех анализах структурные данные указывают на присутствие только одного, фосфатного минерала, который, согласно таблиц В. Михеева [8] и Г. Бушинского [4], является франколитом.

Это подтверждают также приведенные в работе А. Курмана и др.* два рентгеноструктурных анализа створок оболид, параметры кристаллической ячейки которых ошибочно считали характерными для фторапатита:

$$
\begin{array}{lrr}
\text { образец } 032 \text { (Маарду) - } \mathrm{a}_{\mathrm{o}}=9,35 \text { и } \mathrm{c}_{\mathrm{o}}=6,88 ; \text { уд.вес } 3,05 ; \\
\text { образец } 32 \text { (Азери) - } \mathrm{a}_{\mathrm{o}}=9,35 \text { и } \mathrm{c}_{\mathrm{o}}=6,88 ; \text { уд.вес } 3,05 .
\end{array}
$$

Г. Бушинский [4] приводит структурные данные всех минералов группы апатита

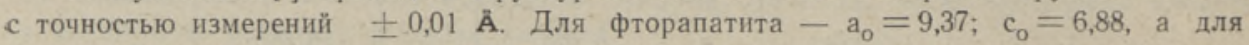
франколита - $\mathrm{a}_{5}=9,34 ; \mathrm{c}_{\mathrm{o}}=6,88$.

На основании вышеприведенного можно сказать, что по структурным данным вещество створок оболид состонт из минерала франколита.

Можно сделать вывод, что фосфатный материал галек и створок оболнд имеет разный минералогический состав и генезис. В гальках кварцевые зерна цементирует хемогенный фосфатный материал - вероятно курскит, а створки оболид состоят из минерала франколита, Скопления этих створок образуют биогенный фосфорит.

\section{ЛИ Т Е Р А Т Р А}

1. А. Г. Бетехтин, Минералогия. Госгеолиздат, М., 1950.

2. Г. И. Бушин ски й, Апатит, фосфорит, вивианит (фосфаты кальция, их минералогия, геология, происхождение и способы изучения), Изд. АН СССР, М., 1952.

3. Г. И: Б у ш н ский, Фосфаты кальцня фосфоритов. Сб. Вопр. геол. агрономических руд, Изд. АН СССР, М., 1956.

4. Г. И. Бу ш и н ск и й, Фосфатные породы. В кн. Справочное руководство по петрографии осадочных пород, Гостоптехиздат, Л., 1958.

5. А. П. Виноградов, Химический элементарный состав организмов моря. Тр. БНОГЕЛ АН СССР, т. IV, 1944.

6. А. В. К азаков, Фосфатные фации, I. Тр. НИУИФ им. Я. В. Самойлова, вып. 145, 1939.

7. И. М. Қурм ан, Об условиях образования фосфоритоносных оболовых песчаников Ленинградской области. Тр. ГИГХС, вып. 2, М., 1955.

8. В. И. М ихеев, Рентгенометрический определитель минералов, Госгеолтехиздат, M., 1957 .

* И. М. Курман, Ю. М. Антипова, П. Е. Морозова. Вещественный состав силурийских фосфоритов Прибалтики. 1955. Рукопись в фондах ГИГХС. 
9. Я. В. С а мо йлов, Месторождения фосфоритов Эстонии. Тр. научн. ин-та по удобрениям, вып. 21, М., 1923.

10. О. Д. Соймонов а, Н. Н. С лудская, К вопросу о структуре фосфоритов. В кн. Агрономические руды СССР, т. 4, М.-Л., 1937.

11. J. G. A n ders s on et N. S a hlbo m, Sur la teneur en fluor des phosphorites suédoises. Bulletin of the Geol. Inst. of the University of Uppsala, Vol. IV, №. 5, 1900.

12. C. G r e w i n g k, Ubersicht der Mineralien und Gesteine Liv-, Est- und Kurlands und ihrer Nutzbarkeit. Sitzungsberichte Naturforscher-Gesellschaft bei der Universität Dorpat, VIII Bd., I H., 1889.

13. C. G ä b e rt, Der Obolensandstein, ein estländisches Rohphosphat. Zeitschrift für prakt. Geol. H. 5, Berlin, 1926.

14. R. Ko ch, Obolusfosforiidi koostisest ja omadustest. ENSV TA Toim. Tehn. ja füüs.mat. tead. seeria. VII köide, nr. 4, 1958.

15. A. K u p f e r, Uber die chemische Constitution der baltischsilurischen Schichten. Archiv f. Naturk. Liv-, Est- u. Kurl., I Serie, V Bd., Dorpat, 1870.

16. K. L i i d e m a n, Fosvoriit väetusainena. Agronoomia, nr. 2, 1922.

17. A ug. M ickwitz, Uber die Brachiopodengattung Obolus Eichwald. Записки императорской Академии наук по физико-математическому отделению, VII серия, т. IV, № 2, С.-Петербург, 1896.

18. C. S ch midt, Agricultur - chemische Untersuchungen. Livländische Jahrbücher der Landwirtschait. Bd. 14, H. 3, Dorpat, 1861.

19. H. W i n k le r, Ober Umfang und Abbauwürdigkeit estländischer Bodenschätze. Mitteilung aus dem Geol. Inst. der Univers. Greifswald. Berlin, 1920.

20. M. W r a n g e ll, Ein estländisches Rohphosphat und seine Wirkung auf verschiedene Pflanzen. Die landwirtschaftliche Versuchsstation Hohenheim. XCVI, Berlin, 1920.

21. A. O p i k, Der estländische Obolenphosphorit. Tallinn, 1929.

$\begin{array}{cc}\text { Институт геологии } & \text { Поступила в редакцию } \\ \text { Академии наук Эстонской ССР } & 20 . \text { II } 1962\end{array}$

\section{OOBOLUSFOSFORIIDI FOSFAATSEST MATERJALIST}

\section{A. Loog}

\section{Resümee}

Eesti alamordoviitsiumi pakerordi lademe kvartsliivakivides esinevad fosfaatsete kaantega puudulukulised brahhiopoodid sugukonnast Obolidae. Nende kaante läätsetaolised kogumikud moodustavad tootmisväärse fosforiidi, mille keskmine $\mathrm{P}_{2} \mathrm{O}_{5}$-sisaldus on $10-15 \%$. Siin esinevad ka hästi ümardunud fosforiitveerised.

Oboliidide kaante keemiline koostis (tabelid 1 ja 2 ; joonis 1) on lähedane frankoliidi omale. Ka oboliidide kaante optiline uurimine ja röntgenostruktuuranalüüs (tabel 4) tõendavad, et oboliidide kaante fosfaatne materjal koosneb frankoliidist. Oboliidide kaaned on algselt fosfaatsed ja nende kuhjumisel moodustus biogeenne fosforiit.

Fosforiitveeristes tsementeerib kvartsiteri kemogeenne kahe eri staadiumi fosfaatne materjal, mis koosneb arvatavasti kurskiidist.

Eesti NSV Teaduste Akadeemia Geoloogia Instituut
Saabus toimetusse

20. II 1962 


\section{UBER DAS PHOSPHATISCHE MATERIAL DES OBOLUSPHOSPHORITS}

\section{A. $\operatorname{Loog}$}

\section{Zusammenfassung}

Im Quarz-Sandstein unterordovizischen Packerort-Stufe kommen in Estland inartikulate Brachiopoden (Familie Obolidae) mit phosphatischen Schalen vor. Diese Schalen liefern Phosphorit, das durchschnittlich 10-15\% $\mathrm{P}_{2} \mathrm{O}_{5}$ enthält, und dessen Bearbeitung durchaus lohnend ist. Hier kommt auch gut abgerundetes Phosphoritgeröll vor.

Die chemische Beschaffenheit der Obolenschalen (Tab. 1 und 2; Abb. 1) ist der des Frankolits nahe. Auch die optische Untersuchung der Obolenschalen und die röntgenologische Analyse ihrer Struktur (Tab. 4) bezeugen, dass das phosphatische Material der Obolenschalen aus Frankolit besteht. Die Obolenschalen sind ursprünglich phosphatisch; durch ihre Anhäufung bildete sich biogenes Phosphorit.

Im Phosphoritgeröll werden die Quarzkörner von chemogenem phosphatischem Material zweier Sonderstadien zementiert, das wahrscheinlich aus Kurskit besteht. 